\title{
AFETO/COGNIÇÃO SOCIAL SITUADA/CULTURAS/LINGUAGENS EM USO (ACCL) COMO UNIDADE DE ANÁLISE DO DESENVOLVIMENTO HUMANO
}

\author{
MARIA DE FÁTIMA CARDOSO GOMES ${ }^{1}$ \\ ORCID: https://orcid.org/0000-0002-6881-3193
}

VANESSA FERRAZ ALMEIDA NEVES ${ }^{2}$

ORCID: https://orcid.org/0000-0003-4094-3639

RESUMO: Este artigo tece uma discussão teórico-metodológica acerca da compreensão do desenvolvimento cultural de bebês e crianças pequenas por meio do Método da Unidade de Análise do ponto de vista da Teoria Histórico-cultural em diálogo com a Etnografia em Educação. Este diálogo, em que uma abordagem interroga e amplia a outra, possibilitou a construção de uma síntese de interpretação das salas de atividades como uma totalidade indivisível - a unidade de análise [afeto/cognição social situada/culturas/linguagens em uso] (ACCL). Partimos do pressuposto de que os afetos são a essência do humano, que deles deriva nossa cognição, nossa capacidade de conhecer o que se produz como culturas, pela mediação semiótica, pelas linguagens em uso, em situações sociais de desenvolvimento. É fundamental dizer que esses conceitos atuam dialeticamente, uns se opondo aos outros e, ao mesmo tempo, constituindo uns aos outros. Somente com base em uma lógica dialética que admite contradições internas entre a objetivação e a apropriação individual das culturas é que essa unidade de análise pôde ser pensada e colocada em prática em nossas pesquisas. Dessa forma, nosso foco está em compreender o que afeta os bebês e as crianças pequenas no sentido de se criar algo novo em seu desenvolvimento, considerando que a linguagem da pessoa humana não se constitui apenas na oralidade, mas também em outras manifestações, como nos gestos, nas expressões faciais, na movimentação corporal, dentre outros. Assim, bebês e crianças pequenas possuem corpos que falam, que sentem, que pensam, que brincam produzindo sentidos para o mundo.

Palavras-chave: Unidade de análise, Teoria Histórico-cultural, Etnografia em Educação; Cognição social situada; Afeto.

\footnotetext{
${ }^{1}$ Universidade Federal de Minas Gerais (UFMG). Belo Horizonte, MG, Brasil.mafa@ufmg.br ou mafacg@gmail.com.

${ }^{2}$ Universidade Federal de Minas Gerais (UFMG). Belo Horizonte, MG, Brasil. vfaneves@ufmg.com. Financiamento de Pesquisa - CNPq e FAPEMIG.

Agradecemos a participação de nossos grupos de pesquisa (GEPSA e EnlaCEI) e aos bebês e crianças, suas famílias e professoras da EMEI Tupi. 


\title{
AFFECT/ SOCIALLY SITUATED COGNITION/CULTURES/LANGUAGES IN USE (ACCL) AS A UNIT OF ANALYSIS OF HUMAN DEVELOPMENT
}

\begin{abstract}
This article aims to discuss the theoretical and methodological discussion of the cultural development of infants and young children through the method of Unit of Analysis from the point of view of Cultural-Historical Theory in dialogue with Ethnography in Education. This dialogue, in which one approach interrogates and extends the other, has enabled the construction of a synthesis of interpretation of the classrooms as an indivisible totality - the unit of analysis [affect/socially situated cognition/cultures/languages in use] (ACCL). We start from the assumption that affections are the essence of the human, that from them derives our cognition, our capacity to know what is produced as cultures, by semiotic mediation, by languages in use, in social situations of development. It is fundamental to say that these concepts act dialectically, opposing each other and, at the same time, constituting each other. Only on the basis of a dialectical logic that admits internal contradictions between objectification and individual appropriation of cultures could this unit of analysis be thought out and put into practice in our research. Thus, our focus is on understanding what affects babies and young children in the sense of creating something new in their development, considering that the language of the human person is not only constituted in orality, but also in other manifestations, such as gestures, facial expressions, body movements, among others. Thus, babies and small children have bodies that speak, feel, think, and play, producing meanings for the world.
\end{abstract}

Keywords: Unit of Analysis, Cultural-Historical Theory, Ethnography in Education; Socially Situated Cognition; Affect.

\section{AFECTO/COGNICIÓN SOCIAL SITUADA/CULTURAS/LENGUAJES EN USO] (ACCL) COMO UNA UNIDAD DE ANÁLISIS DEL DESARROLLO HUMANO}

RESÚMEN: Este artículo hace una discusión teórico-metodológica acerca de la comprensión del desarrollo cultural de bebés y niños pequeños por medio del Método de la Unidad de Análisis desde el punto de vista de la teoría Histórico-cultural en diálogo con la Etnografía de la Educación. Este diálogo en el que un abordaje interroga y amplía al otro, posibilitó la construcción de una síntesis de interpretación de las salas de actividades como una totalidad indivisible - la unidad de análisis [afecto/cognición social situada/culturas/lenguajes en uso] (ACCL). Partimos del presupuesto de que los afectos son la esencia de lo humano, que de ellos deriva nuestra cognición, nuestra capacidad de conocer lo que se produce como culturas, por la mediación semiótica, por los lenguajes en uso, en situaciones sociales de desarrollo. Es fundamental decir que esos conceptos actúan dialécticamente, unos oponiéndose a otros y, al mismo tiempo, constituyendo unos a los otros. Solamente, con base en una lógica dialéctica que admite las contradicciones internas entre la objetivación y la apropiación individual de las culturas es que esa unidad de análisis puede ser pensada y colocada en práctica en nuestras investigaciones. De esa forma nuestro foco está en comprender lo que afecta a los bebés y a los niños pequeños en el sentido de crear algo nuevo en su desarrollo, considerando que el lenguaje de la persona humana no se constituye apenas en la oralidad, sino, también, en otras manifestaciones, como en los gestos, en las expresiones faciales, en el movimiento corporal, entre otros. Así, bebés y niños pequeños cargan cuerpos que hablan, que sienten, que piensan, que juegan produciendo sentidos para el mundo.

Palabras clave: Unidad de Análisis, Teoría Histórico-cultural, Etnografia de la Educación, Cognición social situada, Afecto. 


\section{INTRODUÇÃO}

O que analisar para compreendermos o desenvolvimento cultural de bebês e crianças pequenas? A Teoria Histórico-Cultural nos ajuda a responder a essa questão por meio do conceito de unidade de análise (VIGOTSKI, 1931/1995b). Assim, algumas perguntas nos inquietam: O que é uma unidade de análise do ponto de vista da Teoria Histórico-Cultural? Quais as implicações de investigarmos unidades de análise, em contraste com uma análise por elementos, para um programa de pesquisa que propõe compreender o processo de desenvolvimento cultural de um grupo de bebês? Essas questões revelam o percurso construído individual e coletivamente ao longo de nossas investigações, em um diálogo entre a Teoria Histórico-Cultural e a Etnografia em Educação. Tal diálogo, em que uma abordagem interroga e amplia a outra, possibilitou a construção de uma síntese de análise e interpretação das salas de atividades como uma totalidade indivisível - a unidade de análise [afeto/ cognição social situada/culturas/linguagens em uso] (ACCL) (GOMES, 2020).

Inicialmente, apresentaremos brevemente o programa de pesquisa "Infância e Escolarização". A seguir, explicitaremos as concepções de desenvolvimento cultural e de situação social de desenvolvimento, bem como o método de análise por unidades proposto por Vigotski (1932/2018). Por fim, discorremos sobre a unidade de análise ACCL.

\section{PROGRAMA DE PESQUISA: INFÂNCIA E ESCOLARIZAÇÃO}

O programa de pesquisa longitudinal "Infância e Escolarização" tem como objetivo compreender o processo de desenvolvimento cultural de um grupo de doze bebês a partir do momento de sua entrada na Escola Municipal de Educação Infantil Tupi (EMEI Tupi), em 2017, até sua ida para o Ensino Fundamental, em 2022. O Programa é desenvolvido por meio de projetos de investigação que focalizam temáticas singulares que compõem as vivências desses bebês, tais como o processo de inserção na EMEI Tupi, os processos de imitação, a construção da autonomia dos movimentos psicomotores, a imaginação e as brincadeiras, as práticas de letramento, a constituição da subjetividade, o currículo vivenciado nesse contexto, as relações de amizade e as vivências com os artefatos culturais.

O acompanhamento da turma é realizado pelas pesquisadoras do grupo, com base na Etnografia em Educação e na Teoria Histórico-cultural, por meio da observação participante, das anotações de campo e, principalmente, das filmagens. Dos duzentos dias letivos de cada ano, observamos 42\% em 2017, 35\% em 2018 e 43\% em 2019. Em 2020, a observação da turma foi interrompida em março, devido à pandemia causada pela COVID-19. Permanecemos na turma entre 7 h30 e $17 \mathrm{~h}$ na maioria dos 227 dias observados. O material empírico do Programa é composto por 904 horas das filmagens, fotografias, três cadernos com notas de campo normatizados pelo grupo de pesquisa e os cadernos de campo individuais de cada pesquisadora.

Salientamos, brevemente, que as filmagens acontecem do início ao fim de todos os dias observados, sendo essenciais para o acompanhamento histórico do processo de desenvolvimento cultural dos bebês. As filmagens permitem "coletar, arquivar, recuperar e analisar os registros etnográficos para construir relatos da vida cotidiana das salas de aula" (BAKER; GREEN e SKUKAUSKAITE, 2008, p. 77).

Traçamos alguns princípios que orientam os procedimentos teórico-metodológicos adotados em um diálogo entre a Teoria Histórico-cultural e a Etnografia em Educação. Um desses princípios, refere-se ao fato de que a elaboração dos problemas de pesquisa e do método se desenvolvem de forma conjunta (SPRADLEY, 1980; CORSARO, 1985: ZANELLA et al., 2007, entre outros). Assim, questões específicas, não previstas inicialmente, emergiram do trabalho empírico. Por exemplo, foi possível acompanhar a gênese da brincadeira de rodas no berçário investigado (SILVA e NEVES, 2020), bem como as relações entre a leitura, a escrita e a subjetividade nesse contexto (NEVES, GOMES e DOMINICI, 2021), entre outras questões. Evidencia-se aqui a necessidade de estudarmos as funções psíquicas superiores em seu estágio inicial, ou melhor dizendo, em sua gênese (FONTES et al., 2019). 
Outro princípio refere-se ao fato de o trabalho de campo ser realizado de maneira contínua e comprometida (CORSARO, 1985), por um longo período de tempo, em busca de uma descrição explicativa e analítica, ou uma "descrição densa", nos termos de Geertz (1989, p. 17). Por meio da lógica de investigação etnográfica, é possível buscar um entendimento da comunidade através do ponto de vista de seus membros e descrever as interpretações que eles dão aos acontecimentos que os cercam, isto é, almeja-se uma perspectiva êmica (que leva em conta o ponto de vista dos participantes da pesquisa) e uma perspectiva ética (que diz respeito ao ponto de vista dos participantes) por parte das pesquisadoras. A ética na pesquisa com bebês e crianças pequenas implica a construção de um respeito incondicional ao Outro (NEVES e MÜELLER, 2021). Há um reconhecimento explícito de que as vidas das pessoas (professoras, bebês e famílias) que acompanhamos são irrepetíveis e de que temos o privilégio de vivenciar com elas momentos ricos e diversos. Uma questão ética que se apresenta de maneira pungente refere-se à interpretação dos eventos e, em particular, das ações e falas dos bebês e das crianças pequenas. Traçar limites para o que é possível ser interpretado torna-se fundamental, uma vez que as formas de comunicação e de construção de sentidos ao longo das vivências no contexto da EMEI Tupi nem sempre são acessíveis às pesquisadoras. Nesse sentido, há uma incessante busca por um olhar sensível para o que é passível, ou não, de interpretação.

Um quarto princípio se refere às relações entre os pontos de vista das pessoas pesquisadas com o contexto sócio-histórico no qual esses grupos se inserem. Corsaro (1985) considera como sendo um dos aspectos fundamentais da etnografia o fato de ela ser microscópica e, ao mesmo tempo, holística. Isto é, há uma intenção explícita de relacionar os acontecimentos observados com o contexto mais amplo, reconhecendo que as interações entre os sujeitos são marcadas pelos "encontros entre o local e o global" (STREET, 2003). De fato, o objetivo aqui é compreender, a partir de diferentes perspectivas, o processo de desenvolvimento cultural em um contexto de cuidado e educação coletivos e, igualmente, entender alguns aspectos do mundo no qual bebês, professoras e famílias compartilham suas vivências. Nesse sentido,

Toda e qualquer atividade humana foco de investigação psicológica requer, para sua compreensão e explicação, o olhar sobre os sentidos que têm para os sujeitos em relação, olhar esse que considere a indissociabilidade do sujeito de suas condições de possibilidades e a realidade histórica do contexto do qual ativamente participam (ZANELLA et al., 2007, p.31).

Aliada à compreensão da realidade histórica e social do contexto em que bebês, professoras e suas famílias se encontram - análise sociogenética (GÓES, 2000) -, vincula-se uma análise microgenética, ou seja, "uma análise minuciosa de um processo de modo a configurar sua gênese social e as transformações do curso dos eventos" (GÓES, 2000, p. 11. Grifos nossos). A análise microgenética implica o método da unidade de análise que, por sua vez, requer "destacar do conjunto psicológico integral determinados traços e momentos que conservam a primazia do todo" (VYGOTSKI, 1931/1995a, p. 99-100). Explicitaremos a relevância desse método na próxima seção, bem como discutiremos, na terceira seção desse artigo, o entrelaçamento dialético dos conceitos afeto, cognição social situada, culturas e linguagens em uso.

\section{DESENVOLVIMENTO CULTURAL E SITUAÇÃO SOCIAL DE DESENVOLVIMENTO: CONCEITOS ENTRELAÇADOS PELAS VIVÊNCIAS}

Consideramos a criança como um ser social que se transforma em individual em um processo histórico, dialético e discursivo. Esse ser individual, que é social, torna-se humano, singular, no processo de desenvolver-se culturalmente, na relação com outros humanos em um percurso que não é linear nem progressivo. Assumimos, junto com Vigotski (1932/2018), que esse desenvolvimento é complexo, contraditório e apresenta momentos de evoluções, involuções e revoluções. Para ser desenvolvimento, algo de novo necessita surgir (VIGOTSKI, 1932/2018, p.33), havendo uma metamorfose cultural, o que não está dado pelo nascimento. Nesse processo, o biológico e o cultural se unificam. Assim, 
O desenvolvimento da criança é um processo de constituição e surgimento do homem, da personalidade humana, que se forma por meio do ininterrupto aparecimento de novas particularidades, novas qualidades, novos traços, novas formações que são preparados no curso precedente de desenvolvimento e não estão presentes, já prontas, em tamanhos reduzidos e tímidos, nos degraus anteriores (VIGOTSKI, 1932/2018, p. 35).

Mas, como estudar esse desenvolvimento? Para Vigotski (1932/2018), há que se construir um método de estudo do desenvolvimento infantil que tenha como premissa o "estudo da unidade do desenvolvimento; [este estudo] abrange não apenas um aspecto do organismo, da personalidade da criança, mas todos os aspectos de um e de outro" (VIGOTSKI, 1932/2018, p. 37/38). Isto implica a "decomposição do todo complexo em momentos distintos que o constituem e o formam." (VIGOTSKI, 1932/2018, p. 38). Portanto, o método da unidade de análise não é um método que adote a análise de decomposição em elementos, em partes constituintes elementares que não se relacionam entre si e que formam o todo como um somatório. Para Vigotski (1932/2018), há uma tensão dialética fundamental nesse método, uma vez que ele é definido pela contradição de a unidade de análise ser, por um lado, parte de um todo e, ao mesmo tempo, conter características essenciais do todo. Essa análise em unidades não representa uma generalização, mas "pode explicar diferentes propriedades de uma totalidade complexa" (VIGOTSKI, 1932/2018, p. 41) e requer estabelecer as relações entre as partes e o todo. Dessa forma, é no nível coletivo que as contribuições individuais das crianças, e não somente das professoras, afetam a natureza e a direção (CASTANHEIRA, 2004) do desenvolvimento cultural dos bebês e das crianças pequenas.

A análise do desenvolvimento infantil em unidades pressupõe que, para além de ser descritiva dos sintomas (características externas do desenvolvimento), seja explicativa, isto é, "ao interpretarmos os sintomas, contrapondo-os, temos que chegar aos processos de desenvolvimento que os provocam" (VIGOTSKI, 1932/2018, p. 49). Essa especificidade do método de análise das unidades do desenvolvimento infantil foi denominada por Vigotski (1932/2018) de "caráter genético comparativo" (p. 53). Ou seja, uma vez que não podemos observar o desenvolvimento da mente da criança em si, "podemos apenas comparar [contrastar] o desenvolvimento da sua mente nesse instante e daqui a seis meses, depois mais seis meses e mais seis meses" (VIGOTSKI, 1932/2018, p.53). Para efetivar essa análise, valemo-nos da metodologia da pesquisa longitudinal, holística, contrastiva e etnográfica. Preferimos o uso do termo contrastes, e não o uso de comparações, no sentido de não hierarquizar as diferentes manifestações singulares de desenvolvimento das crianças, nem de estabelecer um padrão único de desenvolvimento que poderia nos levar a estabelecer superioridades e inferioridades entre as crianças.

Portanto, estudamos o desenvolvimento cultural de bebês e crianças pequenas por meio do método da unidade de análise desse desenvolvimento, de maneira global, analítica, genética contrastiva, no sentido de estudar os processos de desenvolvimento que subjazem às diferentes idades, permitindonos esclarecer o caminho que uma criança percorre de uma etapa a outra. Assim, explicitamos semelhanças e diferenças nesses percursos, pois, se apresentamos apenas semelhanças, estaremos em “busca do 'mesmo', que apaga a mudança, o devir, a evolução e desemboca no reducionismo num sentido ou no outro. Se, ao contrário, reconhecermos apenas as diferenças, teremos a singularidade irredutível e não haverá mais conhecimento possível" (THONG, 2007, p.11).

Segundo Veresov e Fleer (2016), “uma compreensão dialética e holística requer uma lógica de análise por unidades e suas relações intrínsecas com o todo, ao invés de uma lógica das interações mecânicas entre elementos." (p. 331/332). Tal compreensão está na base do argumento vigotskiano de que as funções psicológicas superiores, de origem cultural, produtos do desenvolvimento histórico do ser humano, não aparecem nas relações sociais, mas como relações sociais. Portanto, "o que é internalizado das relações sociais não são as relações materiais, mas a significação que elas têm para as pessoas" (SIRGADO, 2000, p.66). Assim,

Vigotski estabelece uma relação de equivalência, não de identidade, entre as relações sociais enquanto estruturas da sociedade e as relações sociais enquanto estrutura social da personalidade. É uma diferença não de natureza, mas de modo de operar segundo se trate de relações da pessoa no mundo público, interpessoal, ou no mundo privado, pessoal (SIRGADO, 2000, p. 16). 
É possível compreender que, se essas funções aparecem como relações sociais, transformações ocorrem nas relações entre as funções psicológicas superiores. Portanto, o processo de desenvolvimento significa não somente o surgimento de resultados qualitativamente novos, mas uma nova estrutura de funções que indica uma reorganização sistêmica (FONTES et al., 2019).

Nesse sentido, podemos pensar na unidade dialética [fala/pensamento] que forma um sistema de sentidos e significados das palavras (MAHN, 2019). Uma função transforma-se na outra, não sendo mais apenas fala e pensamento organizados de maneira isolada. A palavra, como conceito, modifica-se, carrega a generalização, que é propriedade do pensamento; por sua vez, o pensamento se reestrutura por meio da fala. Portanto, a transformação ocorre tanto na fala quanto no pensamento, não sendo mais elementos separados. Forma-se um sistema de sentidos e significados da palavra, uma unidade dialética complexa do desenvolvimento infantil, promovendo o surgimento de algo novo nesse desenvolvimento.

Entretanto, do ponto de vista da Teoria Histórico-Cultural, o desenvolvimento só poderá acontecer em situação social de desenvolvimento, quando as Funções Psicológicas Superiores (memória lógica ou artificial; atenção voluntária, fala, pensamento, imaginação etc.) aparecem como relações sociais, propiciando a descrição e a explicação de algo novo no desenvolvimento infantil. Em outras palavras, as funções psicológicas superiores, inicialmente, são relações sociais que se transformam em funções psicológicas. As funções psicológicas superiores constituem as relações sociais que, ao serem apropriadas pelas crianças, transformam-se em funções psicológicas superiores de cada uma delas, umas constituindo as outras nas situações sociais de desenvolvimento.

A situação social de desenvolvimento pode ser lida como o meio em que a criança vive; mais precisamente, interessa-nos conhecer o papel e o significado desse meio no seu desenvolvimento. No início da vida das crianças, o útero é o seu meio privilegiado, que se amplia ao nascer, articulando-se em torno de espaços estreitos, como seu quarto, ou quarto coletivo, dependendo da escolha da família ou das condições impostas pela situação social em que se nasce; passando aos outros cômodos da casa, a outras casas de familiares e amigos, e, no caso dos bebês que acompanhamos, a EMEI Tupi. Dessa forma, a cada faixa etária, a situação social de desenvolvimento modifica-se, pois o que conta não é apenas o meio em si, mas a relação que as crianças produzem com ele. Ao ocorrer mudanças nas crianças, o meio se modifica também, constituindo as vivências das crianças, "ou seja, não é esse ou aquele momento, tomado independentemente da criança, que pode determinar sua [meio] influência no desenvolvimento posterior, mas o momento refratado através da vivência da criança" (VIGOTSKI, 1932/2018, p.75).

Isso implica reconhecer que uma mesma situação social de desenvolvimento pode ser vivenciada diferentemente por cada uma das crianças do berçário e da sala de atividades, e que é necessário

Saber encontrar a relação existente entre a criança e o meio, a vivência da criança, como ela toma consciência, atribui sentido e se relaciona afetivamente com um determinado acontecimento. Digamos que esse seja o 'prisma' que define o papel e a influência do meio no desenvolvimento do caráter da criança, no seu desenvolvimento psicológico e assim por diante (VIGOTSKI, 1932/2018, p. 77. Grifos nossos).

Nessa perspectiva, a vivência é uma unidade de análise,

(...) na qual se representa, de modo indivisível, por um lado, o meio, o que se vivencia - a vivência está sempre relacionada a algo que está fora da pessoa -, e, por outro lado, como eu vivencio isso [...] é importante saber não apenas quais são as particularidades constitutivas da criança, mas quais delas, em dada situação, desempenharam papel decisivo na definição da relação da criança com determinada situação, enquanto em situação distinta, outras [particularidades] o fizeram (VIGOTSKI, 1932/2018, p. 78).

Portanto, ao investigar as relações da criança com a situação social de desenvolvimento, argumentamos que as mudanças e reações dela vão depender das particularidades de cada uma, de como 
relacionam-se afetivamente com a situação, bem como de seu nível de compreensão, de tomada de consciência, de atribuição de sentidos ao que acontece nessa situação.

O processo de atribuição de sentidos ao que acontece no meio implica, necessariamente, o desenvolvimento do significado das palavras, dado que nos relacionamos com as pessoas pela mediação da fala (ou da mediação da língua de sinais ou tátil). Em cada idade, os significados mudam, dependendo do grau de consciência da criança sobre esses significados, os quais trazem consigo as marcas afetivas e cognitivas da cultura e das linguagens em uso nas diversas situações sociais de desenvolvimento. Para isso, há que se fazerem generalizações, que, no caso de bebês, não são generalizações como conceitos em si, mas de caráter mais concreto, visual e factual (VIGOTSKI, 1932/2018). Sendo assim, para compreendermos os sentidos atribuídos pela criança às suas vivências, é preciso analisar a situação social de desenvolvimento

(...) como uma fonte de desenvolvimento para as formas de atividade e das características superiores especificamente humanas, [...] pois é no meio que existem as características historicamente desenvolvidas e as peculiaridades inerentes ao homem por força de sua hereditariedade e estrutura orgânica. Elas existem em cada homem por ele ser membro de um grupo social, ser uma unidade histórica que vive numa determinada época e em determinadas condições históricas (VIGOTSKI, 1932/2018, p. 90).

Entretanto, o desenvolvimento da criança não repete o desenvolvimento histórico precedente do ser humano (filogênese e sociogênese), pois, na ontogênese, as crianças convivem com adultos e outras crianças. Na convivência com outros é que elas poderão, por exemplo, obter as formas finais ou ideais de desenvolvimento da fala, possibilitando-as de se apropriarem do que antes era uma forma de relação com o meio como relação social, uma forma de colaboração com outras pessoas, e transformar a fala em seu patrimônio interno, em funções internas individuais, ou seja, em funções psicológicas superiores. Tais funções surgem da fala como meio de relação, da atividade externalizada que acontecia entre a criança e as outras pessoas. Essa investigação assume, portanto, o caráter microgenético.

Segundo Oliveira (2009), Vigotski fala em quatro domínios genéticos que interagem na formação do psiquismo: filogênese, ontogênese, sociogênese e microgênese (p. 42/43). Wertsch (1985, p. 55) defende que Vigotski, em consonância com os estudos de H. Werner, identificou dois tipos de microgênese. O primeiro deles é relativo à formação de processos psicológicos em curto prazo, o que requereria repetidas observações do sujeito na realização de determinadas tarefas. O segundo tipo de microgênese é o desdobramento de um ato conceitual ou perceptual no curso de uma fração de segundo. Gomes (2020), com base em Vigotski e Luria (1996) e Oliveira (2009), argumenta que

\footnotetext{
Vigotski se dedica a esse quarto domínio genético antes de morrer, ao rejeitar a visão determinista de desenvolvimento humano, tanto biológico quanto cultural, e, assim, procura compreender as idiossincrasias, o inesperado, as particularidades de cada grupo cultural ou comunidade cultural, aproximando-se dos estudos antropológicos de sua época (GOMES, 2020, p. 42).
}

Dessa maneira, justificamos nosso foco na microgênese: "micro" porque nosso foco está em uma análise minuciosa do desenvolvimento cultural de 12 bebês; e "genético" porque procuramos compreender esses desenvolvimentos como processos cuja origem e transformações necessitam ser entendidas histórica, dialética e discursivamente. Nosso olhar está voltado para as particularidades de cada bebê, evitando tanto a determinação biológica quanto a determinação cultural desses desenvolvimentos (OLIVEIRA, 2009; GÓES, 2000). Nas palavras de Vigotski (1931/1995a, p. 64): "nos últimos anos [década de 30, século XX], a psicologia vem superando o temor diante da valorização cotidiana dos fenômenos e aprende por minúcias insignificantes a descobrir como se manifesta o grande no pequeno".

$\mathrm{Na}$ próxima seção, discorreremos sobre a unidade dialética [afeto/cognição social situada/culturas/linguagens em uso] (ACCL), fundamental para a análise microgenética que 
empreendemos. A unidade ACCL, portanto, é uma síntese teórico-metodológica que norteia nossas investigações dos processos de desenvolvimento cultural das crianças na EMEI Tupi.

\section{[AFETO/COGNIÇÃO SOCIAL SITUADA/CULTURAS/LINGUAGENS EM USO] (ACCL)}

A ancoragem na Teoria Histórico-Cultural em diálogo com a Etnografia em Educação nos permitiu a construção da síntese de análise e interpretação do desenvolvimento cultural dos 12 bebês da EMEI Tupi: a unidade dialética [afeto/cognição social situada/culturas/linguagens em uso] (ACCL). Elaboramos essa unidade de análise porque ela nos possibilita a compreensão do bebê em sua totalidade e singularidades, em sintonia com a busca de Vigotski por uma compreensão das relações entre as funções psíquicas superiores em um sistema complexo. Não se trata, portanto, de tomarmos essas dimensões como elementos isolados; mas, ao contrário, elas constituem uma unidade indivisível, como representado na Figura 1, a seguir.

Figura 1 - Representação da Unidade ACCL

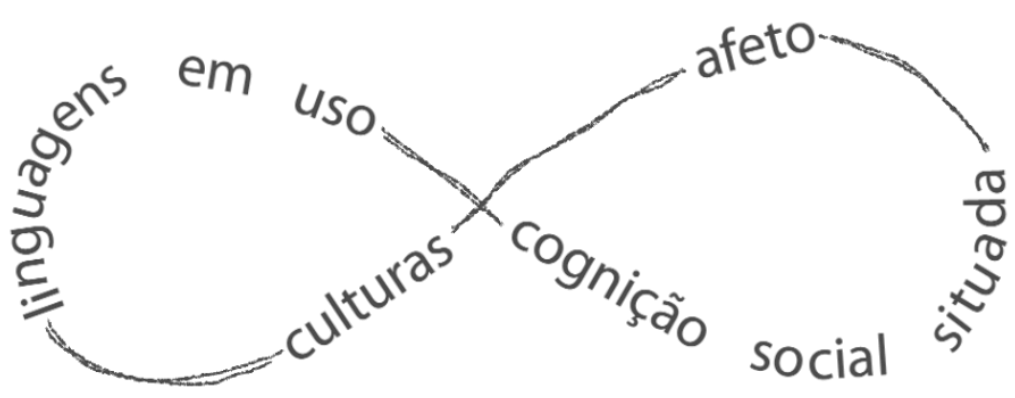

Fonte: elaborada por Aliene Villaça.

A Figura 1 busca explicitar a indissociabilidade das dimensões que compõem a unidade ACCL. Compreendemos que o ponto de partida do desenvolvimento infantil são as emoções, ou seja, as relações emocionais estabelecidas com a situação social de desenvolvimento. Defendemos, com base em Wallon (2008), que a construção da pessoa e do conhecimento se iniciam no período afetivo ou emocional, quando "a afetividade se reduz praticamente às manifestações fisiológicas da emoção, que constitui, portanto, o ponto de partida do psiquismo" (DANTAS, 1992, p. 85). Assim, "este início do ser humano pelo estágio afetivo ou emocional, que aliás corresponde tão bem à imperícia total e prolongada de sua infância, orienta suas primeiras intuições para os outros e coloca em primeiro plano, a sociabilidade" (WALLON, 2008, p. 120) - constituindo o que chamamos de especificamente humano. Por meio das manifestações corporais das emoções, em situação social e situada de desenvolvimento nos meios familiares e escolares, constituímo-nos pessoas com possibilidades de pensar, falar e compreender o mundo. De acordo com Wallon (2008), a psicogênese da motricidade (motor é sempre sinônimo de psicomotor) se confunde com a psicogênese da pessoa - "a razão nasce da emoção e vive de sua morte" - e é esse paradoxo que constitui o ser humano por meio da transformação da "emoção em ativação intelectual" (DANTAS, 1992, p. 86).

De acordo com Dantas (1992), para Wallon, “a atividade emocional é complexa e paradoxal: ela é simultaneamente social e biológica em sua natureza; realiza a transição entre o estado orgânico do ser e a sua etapa cognitiva, racional, que só pode ser atingida através da mediação cultural, isto é, social" (WALLON , 1972, apud DANTAS, 1992, p. 85). Dessa forma, para Wallon (1959),

A consciência afetiva é a forma pela qual o psiquismo emerge da vida orgânica: corresponde à sua primeira manifestação. Pelo vínculo imediato que instaura com o ambiente social, ela garante o acesso ao universo simbólico da cultura, elaborado e acumulado pelos homens ao longo da 
sua história. Dessa forma é ela que permitirá a tomada de posse dos instrumentos com os quais trabalha a atividade cognitiva. Neste sentido, ela lhe dá origem (WALLON, 1959, apud DANTAS, 1992, p. 86).

As manifestações corporais das emoções nos bebês e nas crianças pequenas são o ponto de partida que contagia e enlaça as pessoas, possibilitando-lhes o acesso ao universo simbólico da cultura. As elaborações de Espinosa (1991) sobre o corpo humano nos auxiliam nessa compreensão. Chauí esclarece a concepção de corpo humano para esse autor:

O que é o corpo humano? [...] É uma unidade estruturada: não é um agregado de partes, mas uma unidade de conjunto e equilíbrio de ações internas interligadas de órgãos, portanto é um indivíduo. Sobretudo, é um indivíduo dinâmico, pois o equilíbrio interno é obtido por mudanças internas contínuas e por relações externas contínuas, formando um sistema de ações e reações centrípeto e centrífugo, de sorte que, por essência, o corpo é relacional: é constituído por relações internas entre os órgãos, por relações externas com outros corpos e por afecções, isto é, pela capacidade de afetar outros corpos e ser por eles afetado sem se destruir, regenerando-se com eles e os regenerando. O corpo, sistema complexo de movimentos internos e externos, pressupõe e põe a intercorporeidade como originária (ESPINOSA, 1991 , apud CHAUÍ, 1995, p. 54 itálicos nossos).

Segundo Chauí (1995), ao fazer a defesa do corpo como indivíduo e, ao mesmo tempo, relacional, constituído por relações internas entre os órgãos e externas com outros corpos e por afecções, Espinosa (1991) faz a crítica à ideia de união substancial cartesiana, como também à ideia platônica da alma piloto do corpo e à concepção aristotélica do corpo órgão da alma, isto é, a alma como dirigente do corpo e o corpo como instrumento da alma. Para Espinosa, corpo e alma não estão em uma relação hierárquica de comando. "Corpo e alma são isonômicas, isto é, estão sob as mesmas leis e sob os mesmos princípios, expressos diferentemente" (CHAUÍ, 1995, p. 58). Espinosa (1972) recusa a ideia de faculdades da alma, afirmando que "a alma é, pois, atividade pensante que se realiza como imaginação, querer e reflexão" (idem, p. 58). Nas palavras de Espinosa (1991),

Somos a unidade de um complexo corporal (os milhares de corpos que constituem nosso corpo) e de um complexo psíquico (as inúmeras ideias que constituem nossa mente ou nossa alma). [...] A alma é então definida como consciência das afecções de seu corpo e das ideias dessas afecções; é consciência do corpo e consciência de si. O emprego da palavra constituir, leva ao entendimento de que é da natureza da alma estar ligada internamente ao seu corpo porque ela é atividade de pensá-lo (seja por meio de ideias imaginativas, seja por meio de ideias reflexivas, seja por meio de desejos) e ele [corpo] é o objeto pensado (imaginado, concebido, compreendido, desejado) por ela [alma]. A ligação entre alma e corpo não é algo que acontece a ambos, mas é o que ambos são quando são corpo e alma bumanos. [...] A alma é a ideia das afecções corporais (ESPINOSA, 1991, apud CHAUÍ, 1995, p. 60. Grifos nossos).

Dessa forma, reiteramos que, ao elaborarmos a unidade ACCL, estamos considerando "o corpo e a alma humanos" que não estão em ligação, mas que são unos. Assim, não há como compreender o desenvolvimento cultural dos bebês sem considerar que é por meio das afecções corporais (emoções, desejos, imaginação, querer, vontade) que o ser humano se mobiliza em direção a alguém ou a algo desde os primeiros dias de vida, uma vez que depende essencialmente do outro para sobreviver. Nesses primeiros dias, e ao longo do primeiro ano de vida, "a maior parte das manifestações motoras consistirão em gestos dirigidos às pessoas (apelo): manifestações, agora cheias de nuances, de alegria, surpresa, tristeza, desapontamentos, expectativa etc." (DANTAS, 1992, p. 39).

Em seu primeiro ano de vida, a comunicação emocional do bebê é sua atividade principal, em que a "percepção afetiva, ou seja, emoções e percepção estão ainda indiferenciadas entre si" (VIGOTSKI, 1932/2018, p. 99). Essa comunicação emocional relaciona-se com uma primeira formação sistêmica da consciência humana em que o bebê percebe que um outro cuida dele (TOASSA, 2006, p. 73). Será na relação com as culturas, com as pessoas, que as crianças e os bebês se diferenciarão e nos anos seguintes outras funções, como memória, atenção, fala e pensamento, ganharão predominância no desenvolvimento infantil, em convivência umas com as outras, constituindo-se mutuamente. 
Entretanto, a incompletude do ser humano leva Wallon (2008) a afirmar que somos seres organicamente sociais, isto é, o ser humano, para atualizar sua estrutura orgânica, necessita da cultura, do outro, da mediação semiótica, diria Vigotski (1934/1996). Isso implica fortalecer o argumento da elaboração da unidade de análise ACCL, com base na afirmação de Vigotski:

O pensamento não nasce de si mesmo nem de outros pensamentos, senão da esfera motivacional de nossa consciência, que abarca nossas inclinações e nossas necessidades, nossos interesses e impulsos, nossos afetos e emoções. Por detrás de cada pensamento há uma tendência afetivovolitiva. [...] a compreensão real e completa do pensamento pleno só resulta possível quando descobrimos a trama afetivo-volitiva oculta por trás dele (VIGOTSKI, 1934/1996, p. 342).

Assim, para se descobrir a trama afetivo-volitiva que constitui o pensamento, é necessário desvendar a situação social de desenvolvimento dos bebês - o que nos encaminha para examinar o que se entende por cognição social situada entrelaçada com afetos, culturas e linguagens em uso. Roth e Jornet (2017) argumentam:

(...) pensar não é uma mera atividade subjetiva, entendida na experiência de que pensamentos chegam até nós ("ele pensa") e que pensamentos estão sujeitos ao desenvolvimento orgânico. $O$ ser integral está se tornando no curso da sua vida. Este é o princípio, por exemplo, quando Vygotsky escreve que o entendimento do pensamento requer que compreendamos a pessoa em sua vida integral, onde motivações e interesses da pessoa aparecem, e onde intelecto e afeto são duas manifestações da unidade da pessoa agindo no meio (ROTH E JORNET, 2017, p. 22. Grifos no original. Tradução nossa).

Brown, Collins e Duguid's (1989), estudados por Barrenechea (2000), argumentam que

(...) a cognição de um conhecimento tem uma natureza situada porque existem partes relevantes para seu entendimento que se encontram no contexto de atividade deste conhecimento. Estas partes, no entanto, são subjacentes à cultura do conhecimento e ao sistema de valores que esta cultura emprega para usar o conhecimento em diferentes situações (BROWN, COLLINS e DUGUID’S, 1989 apud BARRENECHEA, 2000, p. 42).

Nessa mesma direção, Agar (1994/2002) defende que há que se quebrar o círculo em torno da língua, e conectá-la com a cultura (AGAR, 2002), modificando nossa visão sobre o mundo e as práticas escolares e não escolares. Para isso, linguagem e cultura não podem ser vistas ou estudadas separadamente. De acordo com Agar, a linguagem está em todas as variedades, em todas as formas da vida diária e constrói um mundo de significados. A linguagem preenche os espaços vazios entre nós com som; a cultura forja a conexão humana através deles [espaços vazios]. Cultura está na linguagem e, linguagem está carregada de cultura (AGAR, 2002, p. 28).

Para esse autor, não há separação entre língua e cultura, gramática, sons e significados, por isso ele cria um neologismo - languaculture (linguagemcultura) - com a intenção de enfatizar a "necessária conexão entre estas duas partes, seja do outro ou meu, ou como sempre quando se torna pessoal, algo que pertence a nós dois" (AGAR, 2002, p. 60). Dessa forma, "langua em languaculture refere-se ao discurso não apenas a palavras ou sentenças, e culture em languaculture refere-se aos significados que incluem e vão além do que os dicionários e a gramática oferecem" (AGAR, 2002, p. 96. Grifos no original).

Isso implica considerar cultura como um sistema complexo de significados e sentidos, como conhecimento de mim e do mundo. Nem linguagem, nem cultura estão fechadas em espaços próprios. Nessa perspectiva, a cultura poderá nos auxiliar a compreender as diferenças de uso das linguagens falada, escrita, corporal, do olhar, do gesto etc. Portanto, cultura "é algo que criamos, algo que inventamos para preencher as lacunas entre mim e os outros, é algo que produzimos na consciência, é um objeto intelectual, que inclui pensamento, intelecto, emoções, contradições e ambiguidades" (AGAR, 2002, p. 138).

Nesse sentido, nem sempre é fácil entender o que o outro diz, como diz e quais são as referências contextuais nas quais se apoia. Para tanto, faz-se necessário buscar, como um dos princípios da etnografia, os pontos relevantes (rich points, no original) da languaculture. Os rich points são aqueles 
momentos em que os participantes de uma conversa assumem posições diferenciadas em relação a uma mesma situação. Tais diferenças causam estranhamento, ou mesmo desconforto, e estão apoiadas no contexto cultural vivenciado por cada um desses participantes e, nesse sentido, dão visibilidade a esses contextos diversos e às diversas vivências das pessoas. Assim, o desenvolvimento compreendido como drama (VIGOTSKI, 1929/2000) pode se tornar visível por meio dos pontos relevantes.

Por meio dos "pontos relevantes, normas, expectativas, papéis e relações, direitos e deveres de pertencimento e participação dos integrantes tornam-se visíveis para os membros [daquela cultura] e, também para os etnógrafos" (GREEN DIXON, ZAHARLIC, 2001/2005, p. 42). Para Agar (2002), quando nos deparamos com os pontos relevantes e buscamos uma compreensão comum, entramos no mundo da languaculture que, por sua vez, possibilita o desmanche do círculo em torno da língua, produzindo linguagens em uso nas situações sociais de desenvolvimento, ou seja, nas vivências.

Dessa forma é pelo discurso, entendido aqui como linguagens em uso ou languacultures, que podemos compreender as afecções corporais dos bebês. Segundo Kelly e Licona (2018), “discurso é linguagem em uso e inclui linguagens falada e escrita, usos de signos e símbolos, e elementos não-lexicais de comunicação como a linguagem do corpo e o olhar nos olhos" (p.11/12). Ampliando essa compreensão, trazemos novamente afetos e pensamentos em Espinosa (1991):

A possibilidade da ação reflexiva da alma encontra-se, portanto, na estrutura da própria afetividade: é o desejo de alegria que a impulsiona rumo ao conhecimento e à ação. Pensamos e agimos não contra os afetos, mas graças a eles. Pela primeira vez, depois de séculos - isto é, desde Aristóteles e Epicuro - a filosofia deixa de diabolizar os afetos, para tomá-los como essência do humano. (ESPINOSA, 1991, apud CHAUÍ, 1995, p. 71).

Seguindo nesta direção, Oliveira (2016) argumenta com Espinosa (1933/2010) que

(...) o afeto é ação ou paixão. Diz respeito às 'afecções do corpo, pelas quais sua potência de agir é aumentada ou diminuída, estimulada ou refreada e, ao mesmo tempo, as ideias dessas afecções' (ESPINOSA, 1933/2010, p.98). Os corpos, na visão spinoziana, mutuamente se afetam, de modo que a mente humana conhece o corpo humano somente a partir das ideias das afecções que afetam esse último (OLIVEIRA, 2016, p.107).

Entretanto, as vivências subjetivas não são capazes de produzir, por si só, a satisfação das necessidades da pessoa. Há que se produzir sentidos pessoais, entrelaçados com os significados sociais, e buscar meios racionais, lógicos e práticos que satisfaçam essas necessidades (VIGOTSKI, 1934/1996). Nas palavras de Monteiro (2015),

(...) a unidade afetivo-cognitiva se expressa sob a forma de significados sociais, que em sua genericidade representam o universo simbólico humano, convertendo-se em sentido na medida em que unifica o significado à finalidade da atividade do indivíduo que pensa, sente e age de forma singular (MONTEIRO, 2015, p. 150).

Dessa forma, afeto e cognição social situada são constitutivos das pessoas em suas relações com as culturas, com o mundo, intersubjetivamente, discursivamente. Isto é, o processo de tomada de consciência de si e do mundo advém da produção de sentidos e significados, por meio das linguagens falada, escrita, do corpo, do olhar, dos símbolos e signos culturais.

Nesse sentido, sustentamos que o desenvolvimento cultural das crianças implica a criação e o uso de signos para a produção de significação. As crianças, nesse processo de desenvolvimento, tornam-se capazes de formular seu próprio pensamento e compreender a fala dos outros, passando da nomeação das coisas por meio de palavras-frase para a combinação das palavras com uso de significados sociais e sentidos pessoais. Dessa forma, "a fala não é nem simples articulação de palavras segundo as regras da língua, [...] nem mera expressão dos vários estados da consciência individual, [...] e, não se reduz ao código, [...] é um evento social" (PINO, 2005, p. 143). Como argumenta Bakhtin (1929/1992), a palavra é o território comum do locutor e do ouvinte, ela é um ato de fala em situação social, é uma 
enunciação, ela dirige-se a um interlocutor (p. 113) e "sem uma orientação social de caráter apreciativo não há atividade mental; mesmo os gritos de um recém-nascido são orientados para a mãe" (p. 114).

Assim, há que se ter foco nas pistas de contextualização dos discursos - verbais, não-verbais e prosódicas (GUMPERZ, 2002). É necessário focalizar o que afeta os bebês e as crianças pequenas no sentido de se criar algo novo em seus desenvolvimentos, considerando que a linguagem da pessoa humana não se constitui apenas na oralidade, mas também em outras manifestações, como nos gestos, nas expressões faciais, na movimentação corporal, dentre outros. Assim, mesmo o jovem bebê é capaz de comunicar-se com o outro, com o mundo e compartilhar significados (OLIVEIRA, 2016).

Isso nos leva a afirmar uma concepção de corpo, como linguagem, que produz sentidos pessoais e significados sociais, ou seja, "A virtude do corpo é poder afetar de inúmeras maneiras simultâneas outros corpos e ser por eles afetado de inúmeras maneiras simultâneas [...]" (CHAUÍ, 1995, p.68/69).

Desta perspectiva, bebês e crianças pequenas carregam corpos que falam, que sentem, que pensam, que brincam, não sendo corpos dóceis condicionados, docilizados.

\section{À GUISA DE CONCLUSÃO...}

Ao tomarmos como premissa que os afetos são a essência do humano, que deles deriva nossa cognição, nossa capacidade de conhecer, porém conhecer o que se produz como culturas, pela mediação semiótica, pelas linguagens em uso, em situações sociais de desenvolvimento, não há outro caminho que o uso do construto teórico-metodológico [afeto/cognição social situada/culturas/linguagens em uso] - ACCL. Isso implica compreender que essa unidade de análise, "como um sistema semântico, da relação sentido-significado, na consciência humana" (MONTEIRO, 2015, p. 185), poderá nos levar à compreensão do desenvolvimento cultural singular de cada um dos 12 bebês de nossa pesquisa na EMEI Tupi, assim como de outros bebês e crianças pequenas, considerando a relação dialética entre o local e o global.

É fundamental dizer que esses conceitos atuam dialeticamente, uns se opondo aos outros e, ao mesmo tempo, constituindo uns aos outros. Somente com base em uma lógica dialética que admite contradições internas entre a objetivação e a apropriação individual das culturas é que essa unidade de análise pode ser pensada e colocada em prática em nossas pesquisas. Somente por meio da lógica dialética que admite a existência de conceitos contrários constituindo uns aos outros é que a ACCL pode ganhar existência como uma síntese provisória, que aqui ganha materialidade nos campos de pesquisa com bebês e crianças pequenas. Uma vez que acreditamos que não se pode explicar os processos psicológicos humanos, que são essencialmente históricos, sociais e culturais, com base em teorias universais e abstratas, que se aplicam a todos os seres humanos, há que se entender "a dialética também histórica dos processos do pensamento humano" (DUARTE, 2001, p. 14).

Esse movimento dialético e histórico permite-nos analisar a singularidade dos bebês e das crianças pequenas, de maneira a entendê-los integralmente, sem que sejam "sacrificadas, sem mais nem menos, às leis gerais e à estatística dos grandes números” (PINO, 2005, p. 185), ou seja, em uma perspectiva microgenética da análise das unidades do drama do desenvolvimento cultural infantil.

\section{REFERÊNCIAS}

AGAR, Michael. Language Shock: understanding the culture of conversation. New York: Macmillan, 2002 (Original, 1994).

BAKER, W. Douglas; GREEN, Judith; SKUKAUSKAITE, Audra. Video-enabled ethnographic research: a microethnographic perspective. In: WALFORD, G (ed.) How to do educational ethnography, 2008. p. 77-114.

BAKHTIN, Mikhail (Volochinov). Marxismo e Filosofia da Linguagem. 6 ed. Tradução: Michel Lahud e Yara Frateschi Vieira. São Paulo: Hucitec, 1992. (Original, 1929-1930). 
BARRENECHEA, Cristina A. Cognição situada e a cultura da aprendizagem: algumas considerações. Educar, Curitiba, n.16, p. 139-153, 2000.

CHAUÍ, Marilena. Espinosa: uma filosofia da liberdade. São Paulo, Editora Moderna, 1995.

CASTANHEIRA, Maria Lúcia. Aprendizagem Contextualizada: discurso e inclusão na sala de aula. Belo Horizonte: Ceale; Autêntica, 2004.

CORSARO, William A. Friendship and peer culture in the early years. Norwood, N.J.: Ablex, 1985. CORSARO, William A. Sociologia da Infância. 2 ed. Tradução: Lia Gabriele Regius Reis. Porto Alegre: Artmed, 2011.

DANTAS, Heloysa. A afetividade e a construção do sujeito na psicogenética de Wallon. In: La Taille, Yves de (org.). Piaget, Vygotsky, Wallon: teorias psicogenéticas em discussão. São Paulo: Summus, 1992.

DUARTE, Newton. Vigotski e o “aprender a aprender” - crítica às apropriações neoliberais e pósmodernas da teoria Vigotskiana, São Paulo: Editora autores Associados, 2001.

ESPINOSA, Benedictus de. Pensamentos Metafísicos - Tratados de Correção do Intelecto; Ética. Seleção de textos Marilena Chauí. São Paulo: Nova Cultural, 1991. [Os Pensadores].

FONTES, Flávio Fernandes et al. Psicologia histórico-cultural, Perezhivanie e além: uma entrevista com Nikolai Veresov. Educ. Soc., Campinas, v. 40, e 0184797, 2019.

GEERTZ, Clifford. A interpretação das culturas. Rio de Janeiro: Guanabara Koogan, 1989.

GÓES, Maria Cecília Rafael de. A abordagem microgenética na matriz histórico-cultural: uma perspectiva para o estudo da constituição da subjetividade. Cadernos CEDES, Campinas, v. 20, n. 50, p. $9-25$, abr. 2000.

GOMES, Maria de Fátima Cardoso. Memorial - Trajetórias de uma Pesquisadora e suas Apropriações da Psicologia Histórico-Cultural e da Etnografia em Educação. Curitiba: Brazil Publishing, 2020.

GREEN, Judith Lee; DIXON, Carol; ZAHARLICK, Ann. Ethnography as a Logic of Inquiry. In: FLOOD, J; LAPP, D; JENSEN, J; SQUIRES, J (Eds.) Handbook for Research on Teaching the English Language Arts. 2 ed. New Jersey: LEA, 2001. p. 201-224.

GUMPERZ, John. Convenções de contextualização. In: RIBEIRO, Branca. Telles; GARCEZ, Pedro (org.) Sociolinguística Interacional. São Paulo: Loyola. 2002. p. 55-76.

KELLY, Gregory J.; LICONA, Peter. Epistemic practices and Science Education. In: MATHEWS, Michael R. (Ed.), History, philosophy and science teaching: New research perspectives. Springer International Publishing, AG, 2018. p. 139-165.

MAHN, Holbrook. Vygotsky's "Speaking/Thinking System of Meaning": An Essential but Overlooked Concept - University of New Mexico. Disponível em: < https://www.academia.edu/547620/Vygotsky s Speaking_Thinking System of Meaning_An Esse ntial but Overlooked Concept $>$. Acesso em: 01 set. 2019.

MONTEIRO, Patrícia Verlingue Ramires. A unidade afetivo-cognitiva: aspectos conceituais e metodológicos a partir da Psicologia Histórico-cultural, p. 193. Dissertação (Mestrado em Psicologia) Universidade Federal do Paraná, Curitiba, 2015.

NEVES, Vanessa Ferraz Almeida; GOMES, Maria de Fátima Cardoso; DOMINICI, Isabela Costa. Literacy in the Making: Integrating Infant's Emotions, Embodiment, and Cognition in a Brazilian Early Childhood Education Center. In: KATZ, Laurie; WILSON, Melissa. (Org.). Understanding the worlds of young children. 1ed. Charlotte: Information Age Publishing, 2021, v. 1, p. 13-36.

NEVES, Vanessa Ferraz Almeida; MÜELLER, Fernanda. Ética no encontro com bebês e seus/suas cuidadores/as. Comissão de Ética em Pesquisa na ANPED. Associação Nacional de Pós-Graduação e 
Pesquisa em Educação (org.). Ética e pesquisa em Educação: subsídios. $1^{\text {a }}$ ed. Rio de Janeiro: ANPEd, v. 2, 2021. p. 94-101.

OLIVEIRA Luciana da Silva de. Um lócus de constituição do humano: vivências e afecções de bebês e educadoras na creche. 2016. p. 278. Tese (Doutorado em Educação). Universidade Federal de Minas Gerais, Belo Horizonte, 2016.

OLIVEIRA, Marta Kohl. Cultura \& Psicologia: questões sobre o desenvolvimento do adulto. São Paulo: Aderaldo \& Rotschild, 2009.

PINO, Angel. As marcas do humano: às origens da constituição cultural da criança na perspectiva de Lev S. Vigotski. São Paulo: Cortez, 2005.

ROTH, Wolff-Michael; JORNET, Alfredo. Understanding Educational Psychology. A Late Vygotskian, Spinozist Approach. Springer International Publishing Switzerland, 1ª ed., 2017.

SILVA, Elenice Brito Teixeira; NEVES, Vanessa Ferraz Almeida. Os estudos sobre a educação de bebês no Brasil. Educação Unisinos, São Leopoldo, v. 24, n. 1, p. 1-19, 2020.

SIRGADO, Angel Pino. O social e o cultural na obra de Vigotski. Educ. Soc., Campinas, v. 21, n. 71, p. $45-78$, jul. 2000.

SPRADLEY, James P. Participant observation. New York: Holt, Rinehart and Winston, 1980.

STREET, Brian. What's "new" in New Literacy Studies? Critical approaches to literacy in theory and practice. Current Issues in Comparative Education, Teachers College, Columbia University, Vol. 5(2), p.77-91, 2003.

THONG, Tran. Prefácio. In: WALLON, Henri. A criança turbulenta: estudos sobre os retardamentos e as anomalias do desenvolvimento motor e mental. Trad. Gentil Avelino Titton. Petrópolis: Vozes, 2007. p. 09-39.

TOASSA, Gisele. Conceito de consciência em Vigotski. Psicologia USP, [S. 1.], v. 17, n. 2, p. 59-83, 2006.

VERESOV, Nicholai; FLEER, Marilyn. Perezhivanie as a theorical concept for researching Young children's development. Mind, Culture, and Activity, v. 23, n. 4, 325-335, 2016. Disponível em: <http://dx.doi.org/10.1080/10749039.2016.1186198>. Acesso: 14/07/2020.

VIGOTSKI, Lev Semiónovitch. Manuscrito de 1929. Educ. Soc., Campinas, v. 21, n. 71, p. 21-44, jul, 2000.

VIGOTSKI, Lev Semiónovitch. 7 Aulas de L. S. Vigotski: sobre os fundamentos da Pedologia. [Trad. Zoia Prestes e Elizabeth Tunes], Rio de Janeiro: E-papers, 2018 (Original, 1932).

VYGOTSKI, Lev Semiónovitch. Análisis de las Funciones Psíquicas Superiores. In: Obras Escogidas: Problemas del Desarrollo de la Psique, Tomo III, Madrid: Aprendizaje: Visor, 1995a, p.97-120. (Original, 1931).

VYGOTSKI, Lev Semiónovitch. Método de Investigación. In: Obras Escogidas: Problemas del Desarrollo de la Psique, Tomo III, Madrid: Aprendizaje: Visor, 1995b, p.47-96. (Original, 1931).

VYGOTSKI, Lev Semiónovitch. Pensamiento y Palabra. In: Obras Escogidas: Problemas de Psicología en General, Tomo II, Madrid: Aprendizaje: Visor, 1996, p.287-348. (Original, 1934).

VYGOTSKY, Lev Semiónovitch; LURIA, Alexander R. Estudos sobre a história do comportamento: símios, homem primitivo e criança. Porto Alegre: Artes Médicas, 1996.

WALLON, Henri. As origens do caráter na criança. São Paulo: Difel, 1972.

WALLON, Henri. Le rôle de l'autre dans la conscience du moi. Enfance, v. 12, n.3-4, 1959. p.277-286. 
WALLON, Henri. Do ato ao pensamento: ensaio de psicologia comparada. Trad. Gentil Avelino Titton. Petrópolis: Vozes, 2008.

WERTSCH, James V. Vygotsky and the social formation of mind. Cambridge: Harvard University Press, 1985.

ZANELLA, Andréa Vieira et al. Questões de método em textos de Vygotski: contribuições à pesquisa em psicologia. Psicol. Soc., Porto Alegre, v. 19, n. 2, p. 25-33, Aug. 2007.

Submetido: $04 / 12 / 2020$

Aprovado: 01/06/2021 